\title{
Investigating the Impact of Entrepreneurial Infrastructure Deficit on Firm Growth
}

\author{
$\underline{\text { Usman Baba Isah }^{1}}$, Zubairu Umaru Mustapha ${ }^{2}$, Mohammed Dokochi ${ }^{3}$, Jaafar Umar ${ }^{4}$ Faiza Maitala ${ }^{5}$ \\ 1, 2,3,4, Federal University of Technology, Minna, Nigeria. ${ }^{5}$ Nile University of Nigeria. \\ babasokomba@gmail.com, uzubairu@gmail.com,dokochi2001@yahoo.com, \\ come2paida@gmail.com, faiza.maitala@nileuniversity.edu.ng
}

\begin{abstract}
Purpose: This study therefore aims to investigate the impact of EI deficit on firm growth, focusing on the growth of SMEs in Nigeria.

Design/methodology/approach: the methods of data collection adopted by the studies (interview, questionnaire and observation

Findings: Empirical findings revealed that the availability of physical infrastructure (constant water supply and good road infrastructure) and the non-physical infrastructure (electricity, government policies/programmes, access to financial support services, incubation centers/platforms, business clusters and entrepreneurship training) improves productivity, profitability, sales, number of customers and consistent growth rate of SMEs.

Research limitations/implications: This was done through a critical review of extant literature (peer reviewed journal articles) on EI which were obtained from reputable data bases and broken down into two basic components of infrastructure (physical and non-physical infrastructure).

Practical implications: The study recommends that government should use fiscal policies to address the economic challenges of SMEs and also invest in the provision of EI facilities to facilitate the growth and development of SMEs in Nigeria.

Originality/value:
\end{abstract}

Paper type: This paper can be categorized as case study paper.

Keywords: Business clusters, critical success factor, deficit, Small and Medium Enterprises.

Received : June $10^{\text {th }} 2019$

Revised : August $17^{\text {th }} 2019$

Published : September $30^{\text {th }} 2019$

\section{INTRODUCTION}

Small and medium enterprises (SMEs) are a global phenomenon and major drivers of global economic growth and development (Ajayi, 2016). SMEs have never been more important than they are today; they reduce poverty and crime rate through creation of employment opportunities, promote creativity and innovation among entrepreneurs, enhance the standard of living of the people, promote research and development (R\&D), contribute to the Gross Domestic Product (GDP) of a country, they also serve as sources of raw materials for industries and, contribute to global economic integration among nations (Galvao et al., 2017; Farran \& Fawaz, 2018; Amoah \& Amoah, 2018).

Investigating The Impact Of Entrepreneurial Infrastructure Deficit On Firm Growth

Usman Baba Isah ${ }^{1}, Z^{2 u b a i r u ~ U m a r u ~ M u s t a p h a ~}{ }^{2}$, Mohammed Dokochi ${ }^{3}$, Jaafar Umar ${ }^{4}$ Faiza Maitala $^{5}$ 
For SMEs to grow and sustain their contributions to the global economy, certain conditions are necessary; these conditions are known as SMEs' "critical success factors" (CSFs) (Abdul et al., 2017). CSFs do not only allow SMEs to sustain their operations and flourish, but also ensure their successful competitive growth and development (Abdul et al., 2017). Nyoni and Bonga (2018) broadly categorized CSFs into three, namely: entrepreneurial, enterprise and environmental factors (3Es). Firstly, the entrepreneurial factors are those factors that are related to the entrepreneur and, they include the entrepreneur's gender, age, level of education, work-experience, psychological profile and entrepreneurial orientation (Joshi \& Mihreteab, 2016; Aftan \& Hanapi, 2018; Nyoni \& Bonga, 2018). Secondly, the enterprise factors are firm related factors which include age and size of firm, business networks, marketing strategies, managerial competence, quality of products and services, customer satisfaction and lastly, human, material and financial resources of the firm (Nyoni \& Bonga, 2018; Boohene, 2018; Aftan \& Hanapi, 2018). Finally, the environmental factors, these are factors that are exogenous to the firm but have an impact on the success or failure of the firm. These factors include political, economic, socio-cultural, technological, legal and regulatory factors including social networks, government support services, availability of the required skilled labour force, financial support services, and lastly, infrastructural facilities (Lampadarios, 2016; Nyoni \& Bonga, 2018; Aftan \& Hanapi, 2018; Badini et al., 2018).

The focus of this study is on some of the basic elements of the third category of CSFs (environmental factors) which has been conceptualised in this study as entrepreneurial infrastructure. Entrepreneurial infrastructure refers to those facilities and services that are available in a given geographic area which encourage the birth of new firms and facilitate the growth of existing SMEs (Galkina \& Kock, 2011; Sen \& Ongsakul, 2018; Medakovic \& Vaskovic, 2018).

The availability of EI serves to create a conducive environment for productive, competitive and profitable entrepreneurial activities (Manggat et al., 2018). Being an important driving force for economic growth and development of any nation, EI also serve to reduce production and transaction costs of businesses thereby facilitating the growth of SMEs and promoting entrepreneurship (Manggat et al., 2018; Goodwin, 2018).

In Nigeria, access to EI has remained a huge obstacle to the growth of SMEs (Igwe et al., 2018). Some of the major challenges militating against the growth of SMEs in Nigeria include unfavourable government policies, multiple taxation, poor access to modern technology, unfair competition, inadequate access to financial support services, and inadequate basic infrastructure (irregular water supply, bad roads, poor electricity supply, insecurity) (Del-Vecchio., et al., 2018; Thanki \& Thakkar, 2018; Ahmad, 2019).Given this back drop, the study sought to investigate the impact of entrepreneurial infrastructure deficit on firm growth in Nigeria. 
A. Literature Review.

\section{Theoretical Framework}

Exogenous growth theory is used as the foundation for the theoretical framework of

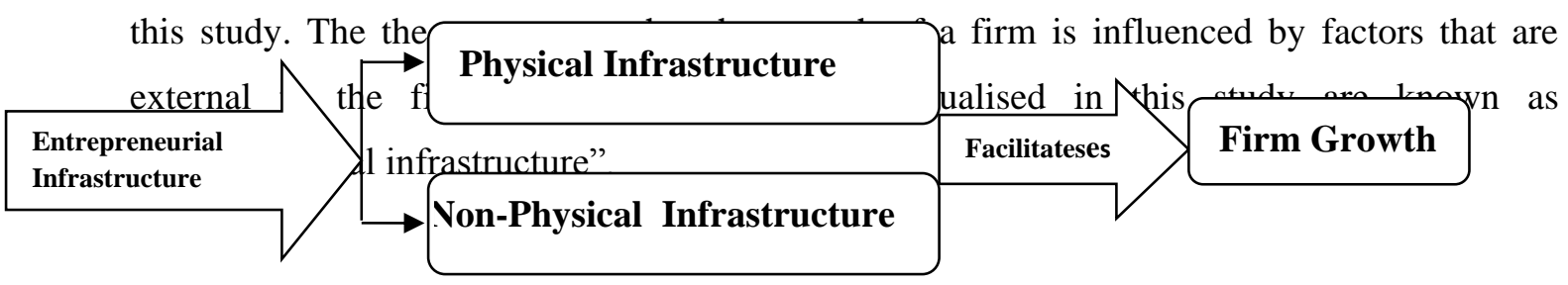

Figure 1.1 Theoretical framework showing how entrepreneurial infrastructure facilitates firm growth based on the "exogenous growth theory".

2. Empirical Review

This section reviewed the findings of prior empirical studies who explored the relationship between EI and firm growth. These prior studies have been broadly categorised into two groups (physical and non-physical infrastructure).

\section{Review of studies in the physical infrastructure group}

Beginning with water infrastructure, Limi (2011) researched on the effects of infrastructure quality on the cost of doing business. The study used firm-level data collected from 26 European and Asian countries through interview of firms' managers to get their perception of whether regular availability of water has an impact on their firms' cost of operation and productivity. It was found that if the incidences of poor water supply are removed completely, firms are estimated to savemore of their operating costs especially those in the manufacturing, construction and hospitality industries thereby increasing their productivity and profitability (Limi, 2011). Switching focus to strictly developing countries, Islam \& Hylan (2018) investigated the effects of unreliable water supplies on the productivity of manufacturing firms. This was achieved by adopting the firm-level World Bank Enterprise Surveys (WBES) covering more than 16,000 manufacturing firms across 103 countries between the years 2009-2015. The study relied on the perception of the business owners and top managers obtained through the use of questionnaires for data collection. It was found that water shortages have a significant and negative impact on firms' productivity, meaning that constant water outages lead to lower productivity of manufacturing firms (Islam \& Hylan, 2018). 
As for transportation infrastructure, Okpara (2011) used subjective rating of firm growth in investigating the factors hindering the growth and survival of small firms in Nigeria. Using questionnaires, data was collected from 211 small business managers and owners in three selected commercial cities (Onitsha, Lagos, Abuja, and Aba) in Nigeria. Findings of the study revealed that poor road infrastructure increase transportation costs which erodes the firms" profit (Okpara, 2011). In another African country (Kenya) within the same year, Nganga, et al. (2011) also conducted a studyto find the relationship between infrastructure availability and firms' growth. To achieve that, perceptual data was obtained from 284 wood-based firm owner/managers who were sampled from three Districts; Nakuru, Kericho and Uasin in the Rift valley province of Kenya. After using observation and questionnaires as the instruments for data collection, it was found that the roads accessed by wood industries are poor, leading to poor efficiency, low productivity and poor growth of the firms (Nganga, et al. 2011).

In addition to the above empirical studies, the next three studies looked at both water and transportation infrastructure concurrently beginning with Carlin (2010) who sought to find the impact of infrastructure on firms' income and productivity by using survey data from 72,000 firms in 95 countries across the world. Judging from managers' perceptions obtained from the questionnaires collected, it was found that improving the quality, availability and reliability of physical infrastructure (good roads and water supply) creates a positive impact on firms' productivity and growth, also that priorities for infrastructure vary widely among industries and countries based on each country's level of economic development (Carlin, 2010). Other findingsof Carlin 2010are discussed in the subsequent subsection.

Similarly, Abdullahi et al. (2015) in finding the impact of finance, training and infrastructure (electricity, transportation, water and telecommunications) on SMEs performance (profitability) used Kano State, Nigeria as a case study with a sample size of 310 SMEs drawn through a simple random sampling from a population of 1530 registered SMEs in the state. After administering closed-ended structured questionnaires to the SMEs the study found that infrastructure (transportation and water supply) has positive and significant effects on the profitability and growth of SMEs (Abdullahi et al., 2015). The other findings of Abdullahi et al. (2015)'s study are discussed under the subsection reviewing the impact of non-physical infrastructure on firm growth.

Another recent study by Effiom \& Edet (2018) sought to ascertain if external environmental factors have an impact on SMEs' profitability in Nigeria. To achieve that, 
questionnaires were sent to 921 SMEs registered with the Corporate Affairs Commission (CAC) in Akwa Ibom, Abia and Cross River states of Nigeria. The study relied on the information on tax returns to measure profitability as well as the perceptions of owner/managers regarding how external environmental factors impacted on their firms' success (increased profitability and sales). Findings revealed a negative relationship exists between non-availability of critical infrastructure (regular water supply and good roads) and SMEs success (profitability and sales). The results implied that critical infrastructure wasa significant factor influencing the profitability of SMEs (Effiom \& Edet, 2018). The remaining parts of the findings of this study would be discussed letter under the nonphysical infrastructure group.

\section{Review of studies in the non-physical infrastructure group}

First for review here is electricity infrastructure. In a study earlier reviewed (Carlin, 2010), it was found that improving the availability of electricity creates a positive effect on firms' growth. Also in addition to other findings of Okpara (2011) discussed earlier, it was found that constant power failure negatively affects productivity \& growth rate of SMEs. Furthermore, Moyo (2013) sought to investigate the effect of the quality of electricity supply on productivity of manufacturing firms in African. 1,598 firms were surveyed from across five African countries including South Africa, Tanzania, Uganda, Zambia and Mauritius. The number of hours per day without electricity and the amount of output lost as a result of power failures were used in measuring the quality of electricity supplied. Relying on the opinion/perception of the firm owners and top management-level employees of the firms investigated, the study found that poor electricity supply has a negative impact on manufacturing firms' productivity in Africa. Moyo's findings have been confirmed by the findings of Abdullahi et al. (2015) who also found that infrastructure (constant electricity supply) has positive and significant effects on the growth of SMEs (Abdullahi et al., 2015).

Even the companies involved in the supply of electricity are not immune of the devastating effect of constant power outage on their businesses. With the objective of finding the impact of improved electricity supply on the growth of Transmission Company of Nigeria (TCN), Famous et al. (2017) study used TCN as case study and carried out a survey of 400 employees of the company using questionnaires. From the perception of the employees, the study found that the quality of electricity supplied by the company and distributed to final consumers(commercial and private) has not resulted to increase in the number of customers they have, neither had it increased consumers' satisfaction. Similar to Moyo's (2013) investigation of five African countries, but now on a larger scale, Bbaale 
(2018) adopted the World Bank Enterprise Survey of 26 African countries in examining the impact of infrastructure quality on the productivity of firms in Africa. The study also found that poor electricity supplies are negatively associated with the productivity of small and medium firms in Africa (Bbaale, 2018).

The second set of studies reviewed under this group investigated the relationship between government policies and firm growth. With the objective of examining infrastructure support activities of Small and Medium Enterprises Development Agency of Nigeria (SMEDAN) in ensuring the growth of SMEs in Ogun State, Nigeria, Oduyoye (2013) designed a survey obtaining data through the use of 135 questionnaires. The study revealed that the provision of Infrastructure Support by SMEDAN was not significant to the growth of some selected businesses (especially cooperative-financed firms) in the state (Oduyoye, 2013). Similarly, Petkovic \& Tesic (2013) sought to find the role of government institutions in the growth of SMEs in Bosnia. To achieve that, 350 questionnaires were distributed to firms in Banja-Luka city of Srpska. From the perceptual responses obtained, it was found that the government institutions supporting entrepreneurship and growth of small businesses were far from meeting the basic requirements of entrepreneurs and business managers in the city (Petkovic \& Tesic, 2013).

Coming back to Nigeria, Mohammed \& Nzelibe (2015) sought to investigate the challenges militating against profitability of SMEs in Nigeria by using questionnaires as instrument for data collection from 244 owners and management level employees of SMEs in major industrial cities (Kano, Ibadan and Lagos) of Nigeria. Major findings from the opinion of the respondents revealed that consistent government policies (example taxation) are the significant factors required for increased profitability among SMEs in Nigeria (Mohammed \& Nzelibe, 2015). Effiom and Edet (2018)'s study which has been discussed earlier under physical infrastructure also revealed a negative relationship between institutions and SMEs growth, meaning that the existing institutions and regulatory framework has compromised SMEs sales and profitability in the states investigated (Effiom \& Edet, 2018).

The third set of studies for reviewed were those that found a relationship between financial support services and firm growth. Coincidentally, all the papers in this sub-section are in the African context, particularly Nigeria except for Nganga, et al. (2011) which is a Kenyan study. In addition to the earlier findings of the study by Nganga et al. (2011), it was also found that firms in the wood industries of Kenya had little or no access to financial services leading to low productivity and slow growth rate of the firms (Nganga, et al. 2011). 
Interestingly, the findings of Nganga et al. (2011) were corroborated by the study of Okpara (2011) which has also been discussed earlier and found that one of the most common constraints hindering small business growth in Nigeria is poor financial support services which is characterized by poor access to capital by small firms due to high interest rates and lack of collateral to be used for securing the loans (Okpara, 2011). The result of Abdullahi et al. (2015) analyses in addition to other findings as earlier discussed, also revealed that access to finance has positive and significant effects on the sales and productivity of SMEs in Nigeria. Again, Effiom \& Edet's (2018) study whose other findings have been earlier discussed also found that access to finance is positively and significantly correlated with SMEs profitability (Effiom \& Edet, 2018).

The fourth group of studies looked at the relationship between information and communications technology (ICT) and firm growth. Okoli et al. (2010) obtained 316 perceptual responses through questionnaire-based survey from both Sub-Sahara African and Latin American business experts and the results revealed that better ICT infrastructure increased the sales, profit and number of customers of small businesses. Similarly, Nganga, et al. (2011) in addition to other findings earlier discussed also found that there is poor access to internet and telecommunications services in Kenya leading to low productivity and poor growth rate of wood based firms. Also back in Nigeria, Nganga, et al., (2011)'s findings have been confirmed by the findings of Abdullahi et al. (2015) who also found that infrastructure (reliable internet and telecommunications services) has positive and significant effects on the profitability and growth of SMEs. This is further corroborated by Oluwaseun \& Moruf (2018) who investigated the strength of ICT adoption on the growth of food and beverages (FB) SMEs in Lagos State, using multi-stage sampling technique, with a sample of 225 questionnaires administered to both owners and employees of the selected FB SMEs. 200 questionnaires were collected and used for the analysis which revealed that ICT adoption has a positive effect on the profitability and growth of the selected Small and Medium Scale FB firms operating in Lagos (Oluwaseun \& Moruf, 2018).

The last non-physical infrastructure component reviewed is for the studies that found a connection between entrepreneurship training and firm growth. First for discussion is the study of Okpara (2011) which has been earlier discussed under physical infrastructure, however, analyses of the study also revealed that one of the obstacles hindering the profitability of firms is poor access to training. Also that inadequate entrepreneurship training/skills acquisition centres hampers the productivity of SMEs (Okpara, 2011). This is confirmed by the findings of Abdullahi et al.,(2015) whose findings also revealed that 
access to entrepreneurship training has positive and significant effects on the profitability and growth of SMEs (Abdullahi et al., 2015).

\section{Method}

This study was carried out using a critical review of extant literature (peer reviewed empirical journal articles) who explored the relationship between entrepreneurial infrastructure and firm growth. The studies were broken down into two basic components of infrastructure (physical and non-physical infrastructure), where components of each of the groups of infrastructure (physical and non-physical) were reviewed one after the other, highlighting the approaches adopted in measuring firm growth (objective or subjective approach), the methods of data collection adopted by the studies (interview, questionnaire and observation) and the growth indicators used in measuring firm growth (productivity, profitability, sales number of customers and customer satisfaction).

\section{A. Summary of empirical the findings}

EI has been found to have a relationship with firm growth. The availability of physical infrastructure (water supply and transportation infrastructure, especially roads) and the nonphysical infrastructure (electricity, government policy, access to financial support services, ICT and entrepreneurship training) have been found to improve productivity, profitability, sales, number of customers and consistent growth rate of small and medium firms(Oluwaseun \& Moruf, 2018; Effiom \& Edet , 2018)).

Based on the review also, three research gaps were identified: methodological, theoretical and geographical research gaps. For the methodological gap, majority of the studies reviewed adopted the use of closed-ended questionnaires as the instruments for data collection (Islam \& Hylan, 2018; Effiom \& Edet, 2018; Bbaale, 2018), only two used interview method (Limi, 2011; Okoli et al., 2010). None of the studies used a combination of both questionnaire and interview methods. As for the theoretical gap, this is the first study to confirm the applicability of 'exogenous growth theory' in investigating the relationship between EI and firm growth in the context of Nigeria. Finally, a geographical gap was identified as the reviewed Nigerian-based studies aimed at finding the nexus between EI and firm growth have been carried out in other geo-political zones of Nigeria (Okpara, 2011; Abdullahi et al., 2015; Effiom \& Edet, 2018). However, none has been found to be carried out in the North Central part of Nigeria.

All the empirical studies reviewed adopted subjective approach in measuring the growth indicator(s) investigated except Effiom and Edet (2018) who adopted the use of both subjective 
and objective approaches. The firm growth indicators adopted in the studies reviewed include productivity, profitability sales, number of customers and customer satisfaction. Some of the studies however used a combination of more than one growth indicator, for example, sales and profitability were used by Effiom and Edet (2018) while Abdullahi et al., (2015) used a combination of profitability and productivity in measuring firm growth. It was also found that most of the studies adopted the use of questionnaires as instrument for data collection (Carlin, 2010; Okoli et al., 2010; Okpara, 2011; Petkovic \& Tesic, 2013; Abdullahi et al., 2015; Mohammed \& Nzelibe, 2015; Famous et al. 2017; Islam \&Hylan, 2018; Effiom \& Edet, 2018; Bbaale, 2018; Oluwaseun \& Moruf, 2018), some used interview (Limi, 2011; Okoli et al., 2010), while others used a combination of questionnaire and observation methods of collecting primary data (Nganga, et al. 2011; Moyo, 2013).

\section{B. Conclusion and Recommendation}

Globally, SMEs are suffering from entrepreneurial infrastructure deficit which has been found to have a relationship with firm growth. The objective of this study was to investigate the impact of EI deficit on firm growth, and through a critical review of empirical peer reviewed journal articles, it was concluded that EI deficit has led to SMEs' reduced efficiency, reduced productivity, weaker competitiveness and poor quality of products and services. It has also increased SMEs costs of production, and distribution of goods and services leading to low profitability or even business closure. In the light of the above, the study recommends that the Nigerian government should use its fiscal policies to address the economic challenges of SMEs, the government and the organised private sector should also invest heavily in the provision of entrepreneurial infrastructural facilities to facilitate the growth and development of SMEs. Lastly, SMEs should also device most economic alternative means of meeting their infrastructural needs and funding rather than depending on public infrastructure.

\section{References}

Abdul, M., Gunasagaran, K., Kamarudin, N. A., \& Mizanur, M. (2017). Critical success factors and challenges of women entrepreneurs in Klang Valley, Malaysia. Journal of Advanced Research in Business and Management Studies, 6(1), 12-23.

Abdullahi, M. S., Ghazali, P. L., Awang, Z., Mohd T. I., Ali, M., \& Salim, N. A. (2015). The effect of finance, infrastructure and training on the performance of small and medium scale enterprises (SMEs) in Nigeria. International Journal of Business and Technopreneurship, 5(3), 421-452.

Aftan, Y., \& Hanapi, M. (2018). The impact of entrepreneurial motivation on small business performance in Iraq. International Journal of Academic Research in Business and Social Sciences, 8(1), 409-419.

Ahmad, K. M. (2019). Crowdfunding as financial option for small and medium enterprises in Nigeria.Pertanika Journal of Scholarly Research Reviews, 4(3), 89-96. 
Ajayi, B. (2016). The impact of entrepreneurial orientation and networking capabilities on the export performance of Nigerian agricultural SMEs. Journal of Entrepreneurship and Innovation in Emerging Economies, 2(1), 1-23.

Amoah, S. K., \& Amoah, A. K. (2018). The role of small and medium enterprises to employment in Ghana. International Journal of Business and Economics Research, 7(5), 151.

Badini, O. S., Hajjar, R., \& Kozak, R. (2018). Critical success factors for small and medium forest enterprises: a review. Forest Policy and Economics, 94, 35-45.

Bbaale, E. (2018). Infrastructure quality and firm productivity in Africa. World Journal of Entrepreneurship, Management and Sustainable Development.14(4) 367-384

Boohene, R. (2018). Entrepreneur's social capital and firm growth: the moderating role of access to finance. Journal of Enterprising Culture.26(03), 327-348.

Carlin, W., Schaffer, M. E., \& Seabright, P. (2010). A framework for cross-country comparisons of public infrastructure constraints on firm growth.Centre for Economic Policy Research, 160.https://papers.ssrn.com/sol3/papers.cfm?abstract

Del-Vecchio, P., Di-Minin, A., Petruzzelli, A. M., Panniello, U., \& Pirri, S. (2018). Big data for open innovation in SMEs and large corporations: Trends, opportunities, and challenges. Creativity and Innovation Management, 27(1), 6-22.

Effiom, L., \& Edet, S. E. (2018). Success of small and medium enterprises in Nigeria: do environmental factors matter?.Journal of Economics and Sustainable Development, 9(4), 117128

Famous I. O., Fandi, G., Muller, Z., Svec, J., \&Tlusty, J. (2017).Effect of improved electricity product development on the business performance of a public electricity transmission company. In Power Africa, 46-51, retrieved from https://ieeexplore.ieee.org/abstract/document/7991198/

Farran, I., \& Fawaz, M. (2018). Role of SMEs in Lebanese economy. Journal of Economics and Management Sciences, 1(2), 78-78.

Galkina, T., \& Kock, S. (2011). The influence of entrepreneurial infrastructure on entrepreneur networking: a comparative case study of Russian and Finnish founding teams. International Journal of Entrepreneurship and Small Business, 13(3), 238-254.

Galvao, A., Ferreira, J. J., \& Marques, C. (2018). Entrepreneurship education and training as facilitators of regional development: a systematic literature review. Journal of Small Business and Enterprise Development, 25(1), 17-40

Goodwin, G. (2018). Water, infrastructure and power: contention and resistance in post-colonial cities of the south. Development and Change, 49(6), 1616-1630.

Igwe, P. A., Ogundana, A. N. A. O. M., Egere, O. M., \& Anigbo, J. A. (2018). Factors affecting the investment climate, SMEs productivity and entrepreneurship in Nigeria. European Journal of Sustainable Development, 7(1), 182-200.

Islam, A., \& Hyland, M. (2018).The drivers and impacts of water infrastructure reliability.1-40 retrieved from https://elibrary.worldbank.org/doi/pdf/10.1596/1813-9450-8637

Joshi, V \& Mihreteab, G (2016). Critical success factors of micro \& small enterprises in Ethiopia: A Review, International Journal of Science and Research, 5 (10), 1056 - 1060

Lampadarios, E (2016). Critical success factors for SMEs: an empirical study in the UK chemical distribution industry. International journal of Business Management, 11 (7), 67-82.

Limi, A. (2011). Effects of improving infrastructure quality on business costs: evidence from firm level data in Eastern Europe and Central Asia. The Developing Economies, 49(2), 121-147. 
Manggat, I., Zain, R., \& Jamaluddin, Z. (2018). The impact of infrastructure development on rural communities: a literature review. International Journal of Academic Research in Business and Social Sciences, 8(1), 647-658.

Medakovic, V., \& Vaskovic, S. (2018). Categories and general characteristics of entrepreneurial infrastructure. Supporting University Ventures in Nanotechnology, Biomaterials and Magnetic Sensing Applications 25-45. DOI 10.1007/978-3-319-61237-9_2

Mohammed, U. D., \& Obeleagu-Nzelibe, C. G. (2015). Entrepreneurial skills and profitability of small and medium enterprises: resource acquisition strategies for new ventures in Nigeria. In Proceedings of 25th International Business Research Conference 64(16), 1-21.

Moyo, B. (2013). Power infrastructure quality and manufacturing productivity in Africa: a firm- level analysis. Energy Policy, 61, 1063-1070.

Nganga, S. I., Onyango, G. M., \& Kerre, B. W. (2011). Determinants of SMEs growth (wood enterprises): infrastructure, technology and collective efficiency. Journal of Geography and Regional Planning, 4(8), 498-504.

Nyoni, T., \& Bonga, W. G. (2018). Anatomy of the small \& medium enterprises critical success factors in Zimbabwe: introducing the 3E model. Journal of Business and Management 1(2) $01-18$.

Oduyoye, O. O., Adebola, S. A., \& Binuyo, A. O. (2013). Empirical Study of infrastructure support and small business growth in Ogun State, Nigeria. Journal of Research and Development, $1(1), 14-22$.

Okoli, C., Mbarika, V. W., \& McCoy, S. (2010). The effects of infrastructure and policy on ebusiness in Latin America and Sub-Saharan Africa. European Journal of Information Systems, 19(1), 5-20.

Okpara, J. O. (2011). Factors constraining the growth and survival of SMEs in Nigeria: implications for poverty alleviation. Management Research Review, 34(2), 156-171.

Oluwaseun, Y., \& Moruf, O. (2018).Impact of ICT adoption on the performance of small and medium scale food and beverages firms in Nigeria. International Journal of Advances in Management and Economics, 3(3), 45-52.

Oyeyemi, A. M., Akoko, A. A., \& Akungba. (2018). Disaggregate energy supply and industrial output in nigeria. International Journal of Economics, Business and Management Research, 2(2), 154172.

Petkovic, S., \& Tesic, J. (2013).SMEs and entrepreneurship development and institutional support in Republic of Srpska (Bosnia and Herzegovina).In Entrepreneurship in the Balkans, 293-315, DOI 10.1007/978-3-642-36577-5_15.

Sen, S. K., \& Ongsakul, V. (2018). Urban climate-proof finance for disaster-resilient infrastructure: issues on competitiveness and sustainability. Environment and Urbanization ASIA, 9(2), 127137.

Thanki, S. J., \& Thakkar, J. (2018). Interdependence analysis of lean-green implementation challenges: a case of Indian SMEs. Journal of Manufacturing Technology Management, 29(2), 295-328. 